Article

\title{
Innovative Self-Cleaning and Biocompatible Polyester Textiles Nano-Decorated with Fe-N-Doped Titanium Dioxide
}

\author{
Ionela Cristina Nica ${ }^{1}$, Miruna Silvia Stan ${ }^{1}$, Anca Dinischiotu ${ }^{1, *}$, Marcela Popa ${ }^{2,3}$, \\ Mariana Carmen Chifiriuc $2,3, *$, Veronica Lazar ${ }^{2,3}$, Gratiela G. Pircalabioru ${ }^{3}$, \\ Eugenia Bezirtzoglou ${ }^{4}$, Ovidiu G. Iordache ${ }^{5}$, Elena Varzaru ${ }^{5}$, Iuliana Dumitrescu ${ }^{5}$, \\ Marcel Feder ${ }^{6}$, Florin Vasiliu ${ }^{6}$, Ionel Mercioniu ${ }^{6}$ and Lucian Diamandescu ${ }^{6}$ \\ 1 Department of Biochemistry and Molecular Biology, Faculty of Biology, University of Bucharest, \\ 91-95 Splaiul Independentei, 050095 Bucharest, Romania; cristinai.nica@gmail.com (I.C.N.); \\ miruna.stan@bio.unibuc.ro (M.S.S.) \\ 2 Department of Botanic-Microbiology, Faculty of Biology, University of Bucharest, 1-3 Aleea Portocalelor, \\ 60101 Bucharest, Romania; bmarcelica@yahoo.com (M.P.); veronica.lazar2009@gmail.com (V.L.) \\ 3 Research Institute of the University of Bucharest-ICUB, University of Bucharest, \\ 91-95 Splaiul Independentei, 050095 Bucharest, Romania; gratiela87@gmail.com \\ 4 Department of Agricultural Development, Democritus University of Thrace, 67100 Xanthi, Greece; \\ empezirt@agro.duth.gr \\ 5 National R \& D Institute for Textiles and Leather Bucharest (INCDTP), 16 Lucretiu Patrascanu, \\ 030508 Bucharest, Romania; iordacheovidiu.g@certex.ro (O.G.I.); elena.varzaru@certex.ro (E.V.); \\ iuliana.dumitrescu@certex.ro (I.D.) \\ 6 National Institute of Materials Physics (NIMP), Atomistilor 405A, 077125 Bucharest-Magurele, Romania; \\ mfeder@infim.ro (M.F.); fvasiliu@infim.ro (F.V.); imercioniu@infim.ro (I.M.); diamand@infim.ro (L.D.) \\ * Correspondence: anca.dinischiotu@bio.unibuc.ro (A.D.); carmen.chifiriuc@gmail.com (M.C.C.); \\ Tel./Fax: +40-21-318-1575 (A.D.); +40-21-318-1576 (M.C.C.)
}

Academic Editor: Thomas Nann

Received: 13 October 2016; Accepted: 7 November 2016; Published: 15 November 2016

\begin{abstract}
The development of innovative technologies to modify natural textiles holds an important impact for medical applications, including the prevention of contamination with microorganisms, particularly in the hospital environment. In our study, Fe and $\mathrm{N}$ co-doped $\mathrm{TiO}_{2}$ nanoparticles have been obtained via the hydrothermal route, at moderate temperature, followed by short thermal annealing at $400^{\circ} \mathrm{C}$. These particles were used to impregnate polyester (PES) materials which have been evaluated for their morphology, photocatalytic performance, antimicrobial activity against bacterial reference strains, and in vitro biocompatibility on human skin fibroblasts. Microscopic examination and quantitative assays have been used to evaluate the cellular morphology and viability, cell membrane integrity, and inflammatory response. All treated PES materials specifically inhibited the growth of Gram-negative bacilli strains after 15 min of contact, being particularly active against Pseudomonas aeruginosa. PES fabrics treated with photocatalysts did not affect cell membrane integrity nor induce inflammatory processes, proving good biocompatibility. These results demonstrate that the treatment of PES materials with $\mathrm{TiO}_{2}-1 \%$ Fe-N particles could provide novel biocompatible fabrics with short term protection against microbial colonization, demonstrating their potential for the development of innovative textiles that could be used in biomedical applications for preventing patients' accidental contamination with microorganisms from the hospital environment.
\end{abstract}

Keywords: photocatalyst; titanium dioxide; polyester textile; antibacterial; skin fibroblasts 


\section{Introduction}

Over the past decade, the emergence and spread of an increasing number of antibiotic-resistant microorganisms has become a serious worldwide concern [1,2]. As all existing natural and chemical agents have lost their efficiency, the search for new methods of sterilization is vital [3]. Photocatalysis has become one of the most effective of all modern techniques because it leads to complete mineralization of organic contaminants, including pathogens [4].

The photocatalytic process has been extensively studied using titanium dioxide $\left(\mathrm{TiO}_{2}\right)$, an ideal material in terms of chemical properties and economical aspect, but having the major disadvantage of radiation's absorption only in the ultraviolet region [5]. For this reason, $\mathrm{TiO}_{2}$ nanoparticles $\left(\mathrm{TiO}_{2} \mathrm{NPs}\right)$ were doped with other metals ( $\mathrm{Ag}, \mathrm{Cu}, \mathrm{Fe}, \mathrm{Zn}, \mathrm{Zr}$ ) [6], non-metals $(\mathrm{C}, \mathrm{N})$, combinations of metals and non-metals, or metals and rare earth elements [7] to extend the photocatalytic activity of $\mathrm{TiO}_{2}$ in visible light, thereby, to obtain increased efficiency of pollution agents' degradation, including pathogens $[8,9]$.

Smart materials with improved features, obtained through the deposition of photoactive nanoparticles on fabrics [10], have gained increasingly more interest on the market. In addition to multifunctional properties, a valuable product should fulfill economic and environmental requirements [11]. The development of innovative technology in order to modify natural materials can be a cheaper alternative than using expensive fibers that already have incorporated performance properties [12]. Usually, new properties can be added to textiles by incorporating functional agents onto their fibers using chemical or physical procedures [13], without any color changes [14]. Noble metal and metallic oxide NPs are the most used to confer antibacterial (against Escherichia coli, Staphylococcus aureus, and Klebsiella pneumoniae) $[15,16]$ and antifungal (against Aspergillus niger and Candida albicans) activities [17,18]. In addition to these, the photocatalysts were intensively investigated to develop multifunctional textiles with special properties, such as self-cleaning and stain repellence [19-21], ultraviolet (UV) and electromagnetic radiation (EMR) shielding [22], hydrophobic-hydrophilic [23], wrinkle-freeness, static elimination, and electrical conductivity [24-26]. Consequently, different photocatalytic fabrics based on cotton, polyester, wool, polyamide, or cellulose fibers were designed in previous years $[27,28]$. These fabrics with enhanced functionalities are of great interest for medical environments, textile and food industries due to their ability to inhibit the formation of pathogen biofilms, stop the spread of nosocomial infections, and remove the infection sources [29].

In this study, polyester (PES) fabrics $\left(142 \mathrm{~g} / \mathrm{m}^{2}, 0.295 \mathrm{~mm}\right.$ thickness) were treated with $\mathrm{TiO}_{2}$ particles co-doped with $1 \%$ iron and nitrogen atoms $\left(\mathrm{TiO}_{2}-1 \% \mathrm{Fe}-\mathrm{N}\right)$ according to the methods described in our previous work [28]. The Fe-N doping was chosen due to their physical particularities: nitrogen is able to extend the absorption in the visible region and iron can reduce the electron-hole recombination $[30,31]$. Depending on the phase composition and band gap, the photodegradation efficiency can be improved by 75\% under visible light [32]. In a first step, the fabrics were immersed in a fresh particle suspension and, after that, new fabrics were soaked in the remaining dispersion from the first treatment and, consecutively, a polyacrylic binder was used to fix the particles. Using this approach, the amount of doped $\mathrm{TiO}_{2}$ particles which were released into the environment and the water, and the chemicals' consumption, were reduced [28].

Scanning electron microscopy (SEM) and energy dispersive X-ray spectroscopy (EDX) analysis were used to characterize the morphology of the coated fibers and the nanoparticles' distribution on the fibers. The photocatalytic performance and self-cleaning efficiency of $\mathrm{TiO}_{2} \mathrm{NPs}_{\text {deposited on PES }}$ fabrics was evaluated by observing the changes in color parameters after staining with methylene blue (MB) or coffee, and exposure to visible and ultraviolet light. In addition, the antimicrobial activity was tested against Gram-negative (E. coli, Pseudomonas aeruginosa) bacterial reference strains using standardized quantitative assays. Finally, biocompatibility was assessed on CCD-1070Sk normal human dermal fibroblasts by cellular morphology, viability, and cell membrane integrity analyses after 6 and $12 \mathrm{~h}$ of exposure to the NP-treated fabrics to obtain novel and valuable experimental data for further in vivo purposes. 


\section{Results}

\subsection{Characterization of Photocatalysts}

X-ray diffraction (XRD), X-ray photoelectron spectroscopy (XPS), transmission electron microscopy (TEM) and Mössbauer spectroscopy were used to study the structure and morphology of the obtained nanoscaled photocatalysts.

In Figure 1 the XRD patterns of both photocatalysts are depicted. Rietveld refinements revealed the presence of a prevailing anatase phase accompanied by a brookite phase in both samples. The crystallite sizes (given by Scherrer equation [33]) are in the range of 10-12 nm for the anatase phase and 8-11 $\mathrm{nm}$ for the brookite phase, respectively (Table 1). XPS and Mössbauer spectroscopy certified the presence of nitrogen and $\mathrm{Fe}^{3+}$ in the obtained samples. The photocatalytic tests, in both UV and visible spectral regions, were performed by means of a PCC-2 (Ulvac-Riko Inc., Yokohama, Japan \& ULVAC GmbH, Ismaning, Germany) photocatalytic checker. A detailed analysis was presented in a previous paper [28].

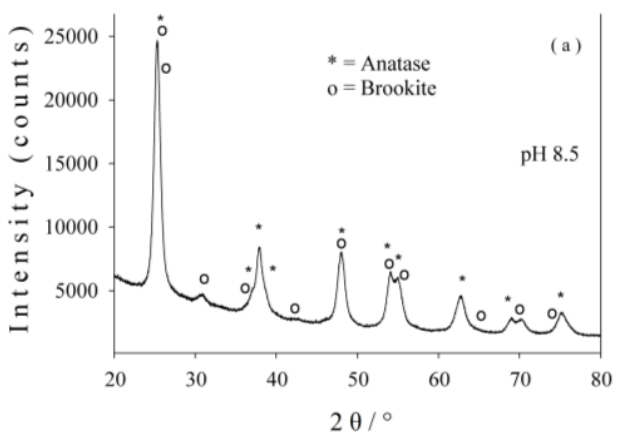

(a) $\mathrm{pH} 8.5$

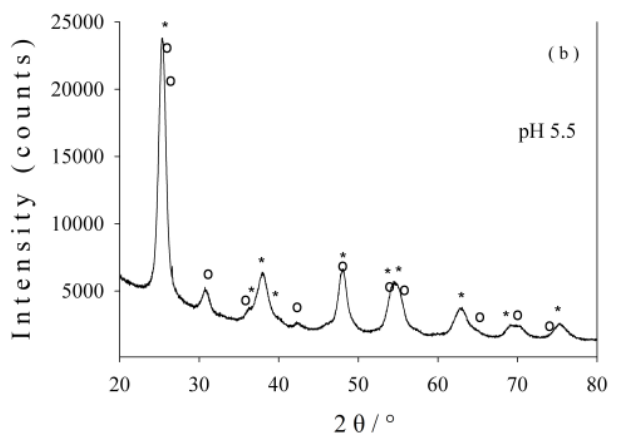

(b) $\mathrm{pH} 5.5$

Figure 1. X-ray diffraction (XRD) patterns of photocatalyst 1 (a) and photocatalyst 2 (b).

Table 1. Phase content and crystallite size of hydrothermally-synthesized photocatalysts.

\begin{tabular}{ccc}
\hline Sample & Crystallite Size $\mathbf{( n m )}$ & Phase Assignment/Abundance (wt \%) \\
\hline \multirow{2}{*}{ (Photocatalyst 1) } & 12.3 & Anatase 85.3 \\
& 8.5 & Brookite 14.7 \\
\hline \multirow{2}{*}{ (Photocatalyst 2) } & 10.4 & Anatase 79.4 \\
& 11.6 & Brookite 20.6 \\
\hline Errors & \pm 1.5 & \pm 1.4 \\
\hline
\end{tabular}

TEM images (Figure 2a,b) display the powder morphology of nanoscaled photocatalysts obtained by hydrothermal treatment and co-precipitation at different $\mathrm{pH}$ values corresponding to $\mathrm{pH} 8.5$ (photocatalyst 1) and pH 5.5 (photocatalyst 2). A predominant quadratic morphology can be observed in the first case, and a combined morphology (triangular, spherical, etc.) can be noticed for the second photocatalyst. Furthermore, the particle distribution was evaluated for the photocatalysts 1 and 2, as displayed in Figure 2c,d, respectively. The statistical measurements were performed on more than 100 particles. The mean size of $\sim 15 \mathrm{~nm}$ with standard deviation $\sim 2.8 \mathrm{~nm}$ corresponding to $\mathrm{pH} 5.5$ decreased to $\sim 10 \mathrm{~nm}$ with standard deviation, and $\sim 4 \mathrm{~nm}$ in the case of $\mathrm{pH} 8.5$, in rather good agreement with $\mathrm{XRD}$ results (Figure 1). 


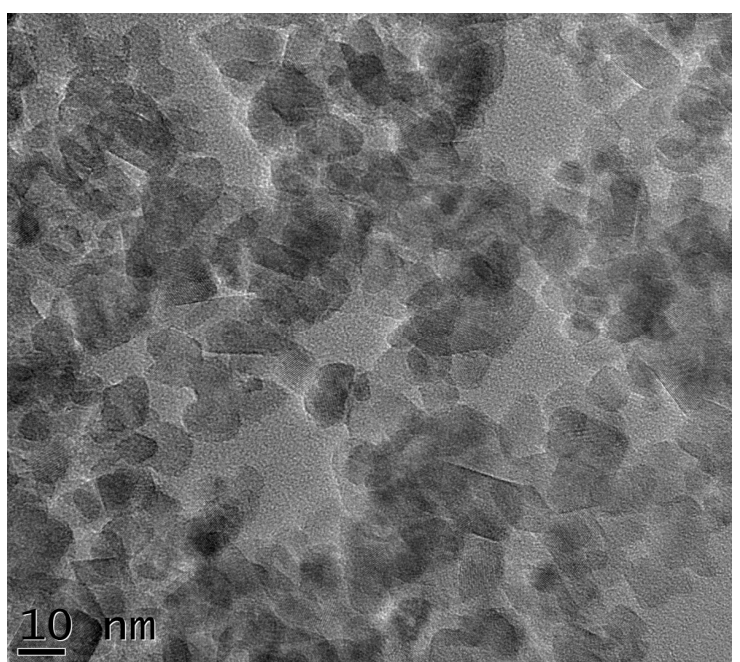

(a) $\mathrm{pH} 8.5$

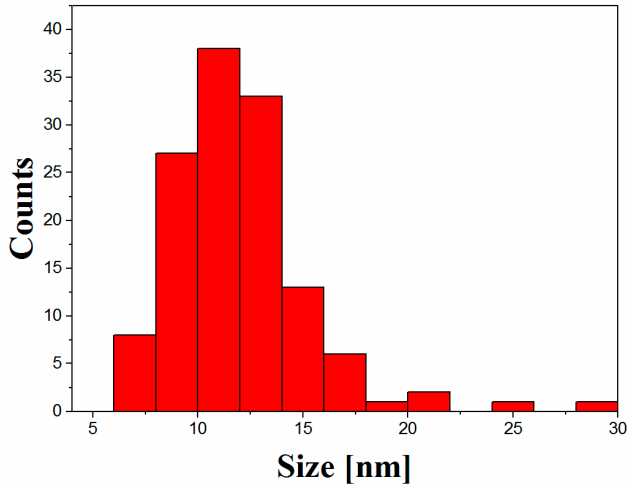

(c) $\mathrm{pH} 8.5$

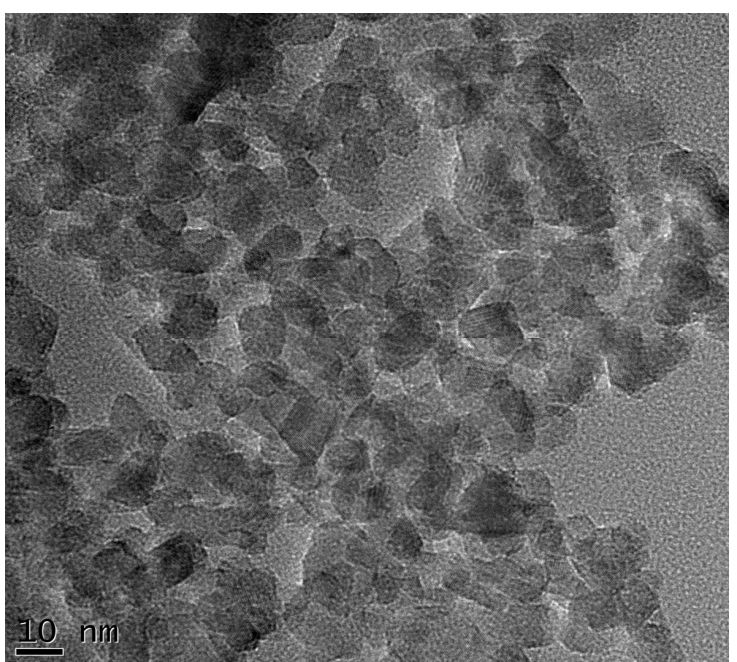

(b) $\mathrm{pH} 8.5$

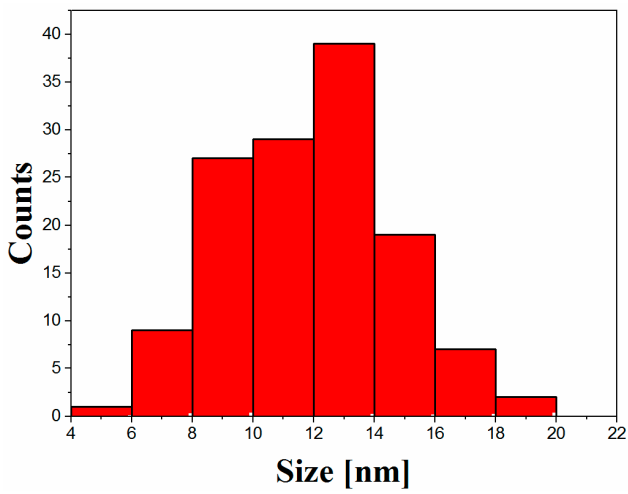

(d) $\mathrm{pH} 5.5$

Figure 2. Transmission electron microscopy (TEM) images $(\mathbf{a}, \mathbf{b})$ of $\mathrm{TiO}_{2}-1 \% \mathrm{Fe}-\mathrm{N}$ photocatalysts and their corresponding size distribution (c,d) for: $\mathrm{pH} 8.5$ (photocatalyst 1) and $\mathrm{pH} 5.5$ (photocatalyst 2).

\subsection{SEM/EDX Analysis of the Treated Fabrics}

Scanning electron microscopy (SEM) analysis (Figure 3) showed the modification of the polyester fibers, which are non-uniformly coated by doped $\mathrm{TiO}_{2}$ particles. Regardless of the photocatalyst used, most of the particles form clusters. Their sizes varied slightly higher in the case of treatment with the photocatalyst $2(270-288 \mathrm{~nm})$ compared to photocatalyst $1(132.6-278 \mathrm{~nm})$. The polyacrylic binder (ITOBINDER AG, abbreviated ITO) induced a higher aggregation of the particles as it can be seen from SEM images, where the size of the particles deposited by using only the photocatalysts were lower than that deposited by re-immersing the materials into polyacrylic binders. These findings are in accordance with other studies where the fabrics' treatment with $\mathrm{TiO}_{2}$-acrylate revealed more agglomerated particles [34].

Physical characteristics (weight, thickness, fiber diameter, air permeability, water vapor resistance, and surface resistivity) were investigated initially and after the fabrics' treatment to evaluate the effect of co-doped $\mathrm{TiO}_{2}$ nanoparticles on the properties of polyester material (Table 2). In addition, the percentage weights of Ti K are shown in Table 3. 


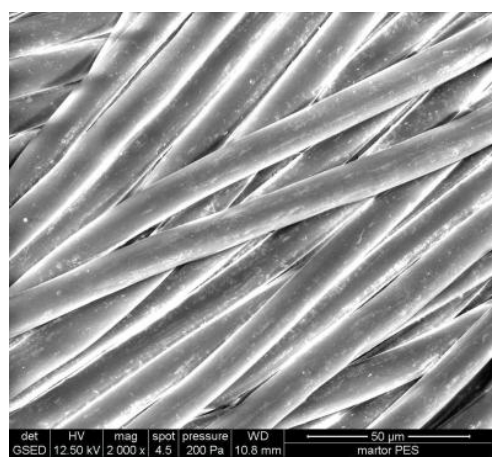

(a)

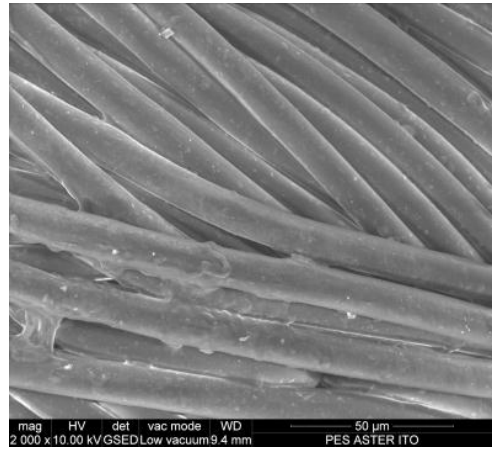

(d)

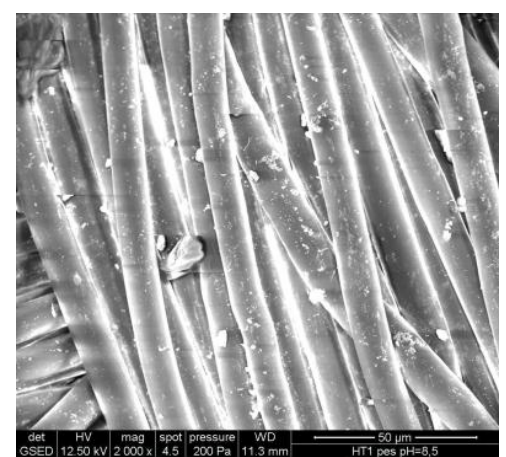

(b)

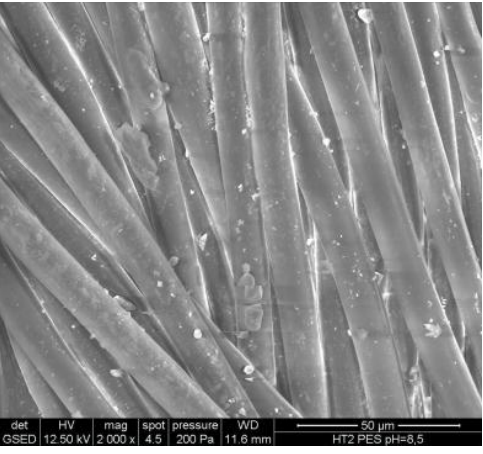

(e)

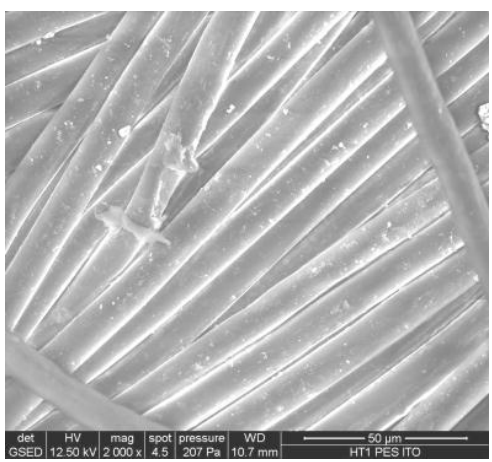

(c)

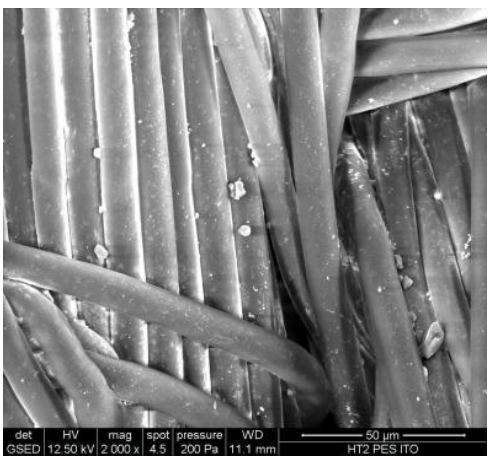

(f)

Figure 3. Scanning electron microscopy (SEM) images of polyester fabrics: Control-polyester (PES) fabric (a); HT1-PES fabric treated with $\mathrm{TiO}_{2}-1 \% \mathrm{Fe}-\mathrm{N}$ (photocatalyst 1) (b); HT1 polyacrylic binder (ITO)-PES fabric treated with $\mathrm{TiO}_{2}-1 \% \mathrm{Fe}-\mathrm{N}$ (photocatalyst 1) and ITO (c); PES ITO-PES fabric treated with polyacrylic binder (ITO) (d); HT2-PES fabric treated with $\mathrm{TiO}_{2}-1 \% \mathrm{Fe}-\mathrm{N}$ (photocatalyst 2) (e); HT2 ITO-PES fabric treated with $\mathrm{TiO}_{2}-1 \% \mathrm{Fe}-\mathrm{N}$ (photocatalyst 2) and ITO (f).

Table 2. Physical characteristics of initial and coated polyester fabrics.

\begin{tabular}{|c|c|c|c|c|c|c|}
\hline \multirow{2}{*}{ Parameters } & \multicolumn{5}{|c|}{ Results for Each Sample } & \multirow{2}{*}{ Standard } \\
\hline & Initial & HT1 & HT1 ITO & HT2 & HT2 ITO & \\
\hline Weight $\left(\mathrm{g} / \mathrm{m}^{2}\right)$ & 142 & 149.65 & 150 & 150.55 & 150 & SR EN ISO 12127/2003 \\
\hline $\begin{array}{c}\text { Thickness (mm) } \\
\text { (surface: } 20 \mathrm{~cm}^{2}, \Delta \text { pres: } \\
100 \mathrm{~Pa} / 200 \mathrm{~Pa}, t: 19.2^{\circ} \mathrm{C}, \\
R H: 63.2 \%)\end{array}$ & 0.295 & 0.36 & 0.36 & 0.39 & 0.36 & SR EN ISO 5084/2001 \\
\hline Fiber diameter $(\mu \mathrm{m})$ & 11.69 & 11.13 & 10.72 & 11.33 & 11.18 & Projection microscope \\
\hline $\begin{array}{c}\text { Air permeability }\left(\mathrm{L} / \mathrm{m}^{2} / \mathrm{s}\right) \\
\left(20 \mathrm{~cm}^{2}, 100 \mathrm{~Pa}, t: 19.2^{\circ} \mathrm{C}\right. \\
\text { RH: } 63.2 \%)\end{array}$ & 173.3 & 153 & 106.33 & 86.33 & 99.86 & SR EN ISO9237:1999 \\
\hline $\begin{array}{l}\text { Water vapor resistance } \\
\left(\mathrm{m}^{2} \mathrm{~Pa} / \mathrm{W}\right)\end{array}$ & 6.519 & 6.439 & 6.679 & 5.999 & 6.678 & $\begin{array}{c}\text { SR EN 31092/A1/2013 } \\
\text { ISO } 11092 / 1997\end{array}$ \\
\hline $\begin{array}{l}\text { Surface resistivity }\left(\times 10^{14} \Omega\right) \\
\quad\left(t: 24.1^{\circ} \mathrm{C}, R H: 45.4 \%\right)\end{array}$ & 1.75 & 2.2 & 2.6 & 1.3 & 2.7 & SR EN 1149-1:2006 \\
\hline
\end{tabular}

Notes: $t$ is temperature; pres, pressure; $R H$, relative humidity; HT1, polyester fabric treated with photocatalyst 1 ; ITO, polyacrylic binder; HT2, polyester fabric treated with photocatalyst 2; SR EN ISO, European Standard of the International Organization for Standardization adopted as Romanian Standard. 
Table 3. Energy-dispersive X-ray spectroscopy (EDX) analysis of polyester fabrics treated with $\mathrm{TiO}_{2}-1 \%$ Fe-N photocatalysts.

\begin{tabular}{cccccc}
\hline Element (wt \%) & Control & HT1 & HT1 ITO & HT2 & HT2 ITO \\
\hline C K & 61.51 & 65.43 & 58.57 & 62.12 & 53.74 \\
O K & 38.49 & 32.58 & 35.78 & 34.34 & 36.99 \\
Ti K & 0 & 1.99 & 5.66 & 3.54 & 9.27 \\
\hline Total & 100 & 100 & 100 & 100 & 100 \\
\hline
\end{tabular}

As shown in Table 2, the results demonstrated that no significant changes were induced by the treatment, except air permeability, especially in the case of fabrics covered with photocatalyst 2 (HT2). This behavior can be attributed to the larger size of photocatalyst 2 nanoparticles $(\sim 15 \mathrm{~nm})$ in comparison with photocatalyst $1(\sim 10 \mathrm{~nm})$ which coated the fibers and penetrated the pores. Certainly, an important role in the decrease of air permeability was played by the polyacrylic binder due to the film formation on the material's surface. The water vapor resistance showed only minor modifications, indicating that the comfort properties were conserved. The slight increase of the material weight $(\sim 5 \%)$ and thickness was due to the deposition of photocatalytic compounds and polyacrylic binder. The surface resistivity values indicated a higher increase for the fabrics covered with a polymeric film than for those treated only with nanoparticles.

Due to the interaction of negatively charged groups $\left(-\mathrm{COO}^{-}\right)$with the positive charges of photocatalysts, the polyacrylic binder improves the adherence of the particles at the material surface allowing the deposition of a much larger amount of photocatalysts on the polyester fabric. If we compare the amount of photocatalysts deposited by using the dispersion remaining from the first treatment (fabrics named HT1 ITO and HT2 ITO) with that obtained by using the initial dispersion (fabrics named HT1 and HT2), it is clear that the re-used dispersion in combination with polyacrylic binder almost tripled the quantities of particles deposited on the fabrics. As the results demonstrate, the amount of photocatalyst 2 deposited on fabrics was double in comparison with photocatalyst 1.

\subsection{Evaluation of the Photocatalytic Efficiency}

Photocatalytic activity assessed in terms of chromaticity coordinates of the treated materials, stained with methylene blue and coffee and exposed to light, is shown in Table 4.

The color differences between the treated samples and the control were measured via the CIE $L^{*} a^{*} b^{*}$ coordinates specified by the "Commission Internationale de l'Éclairage" (CIE) [35], where: $L^{*}$ represents lightness $\left(d L^{*}\right.$ is the lightness difference between sample and control and indicates a lighter color if positive and darker if negative), $a^{*}$ signifies the red/green value (if $d a^{*}$ is positive, the sample is redder than the control, otherwise is greener), and $b^{*}$ is the yellow/blue value (if $d b^{*}$ is positive, the sample is yellower than the control, otherwise it is bluer), and $d E^{*}$ represents the total color difference and is calculated according to the following formula: $d E^{*}=\sqrt{d L^{* 2}+d a^{* 2}+d b^{* 2}}$.

Table 4. Color differences $\left(d E^{*}\right)$ of the polyester fabrics treated with $\mathrm{TiO}_{2}-1 \% \mathrm{Fe}-\mathrm{N}$ photocatalysts, stained with $0.01 \mathrm{~g} / \mathrm{L}$ methylene blue (MB) or coffee, and exposed to visible, ultraviolet (UV) and solar light.

\begin{tabular}{ccccccc}
\hline \multirow{2}{*}{ Sample } & \multicolumn{2}{c}{ Stained with Methylene Blue } & \multicolumn{3}{c}{ Stained with Coffee } \\
\cline { 2 - 7 } & $\boldsymbol{d} E^{*}$ Vis & $\boldsymbol{d} \boldsymbol{E}^{*} \mathbf{U V}$ & $\boldsymbol{d} \boldsymbol{E}^{*}$ Solar & $\boldsymbol{d} \boldsymbol{E}^{*}$ Vis & $\boldsymbol{d} \boldsymbol{E}^{*} \mathbf{U V}$ & $\boldsymbol{d} \boldsymbol{E}^{*}$ Solar \\
\hline Control & 3.34 & 3.21 & 4.77 & 4.92 & 1.3 & 1.62 \\
HT1 & 7.64 & 3.21 & 8.47 & 4.92 & 2.01 & 2.47 \\
HT2 & 9.06 & 6.2 & 6.35 & 2.84 & 2.96 & 6.42 \\
HT1 ITO & 7.51 & 5.91 & & 1.69 & 1.77 & \\
HT2 ITO & 1.86 & 2.4 & & 2.45 & 1.48 & \\
\hline
\end{tabular}


As it can be seen in Table 4, the most efficient discoloration took place under visible and solar radiation for both types of stains. The improved photocatalytic activity could be attributed to the extended absorption [36] of the light due to the synergistic effect of Fe-N co-doping of $\mathrm{TiO}_{2}$ resulting in the formation of narrow band gap level, reducing the excitation energy of electron from the valence band to conduction band [37] and improving the generation of electron-hole pairs. Depending on synthesis technology the optical absorption edge is shifted to $675 \mathrm{~nm}$ [38].

The correlation between the percentage weights of Ti K and the color differences $\left(d E^{*}\right)$ of the polyester fabrics treated with $\mathrm{TiO}_{2}-1 \% \mathrm{Fe}-\mathrm{N}$ photocatalysts and stained with methylene blue or coffee is shown in Figure 4. If under visible and UV light, the HT2 fabric stained with methylene blue and containing an average amount of $\mathrm{TiO}_{2}(3.54 \% \mathrm{Ti} \mathrm{K})$ had the highest photocatalytic efficiency, under solar radiation, the highest activity was shown for the HT1 fabric containing the lowest amount of $\mathrm{TiO}_{2}(1.99 \% \mathrm{Ti} \mathrm{K})$. In the case of the materials stained with coffee, the highest photocatalytic efficiency under visible light was shown by the HT1 material on which surface it was found $1.99 \% \mathrm{Ti}$ K and, under UV and solar light, by the HT2 material containing 3.54\% Ti K.

PES fabrics stained with methylene blue

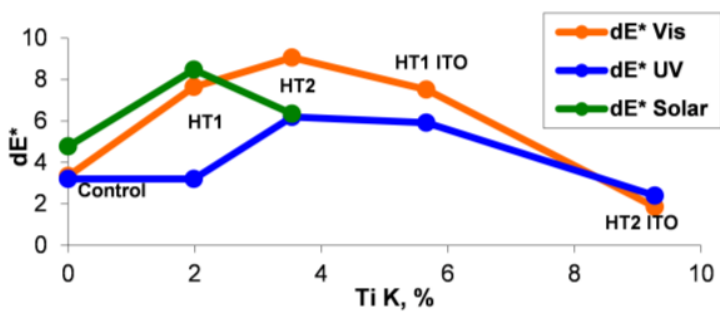

(a) methylene blue stain
PES fabrics stained with coffee

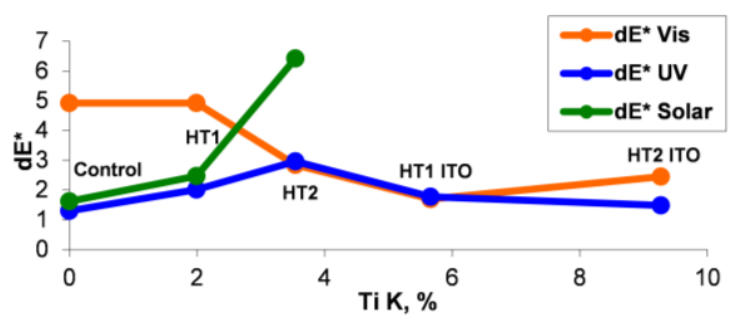

(b) coffee stain

Figure 4. Correlation between percentage weights of $\mathrm{Ti} \mathrm{K}$ and color differences $\left(d E^{*}\right)$ of the polyester fabrics treated with $\mathrm{TiO}_{2}-1 \% \mathrm{Fe}-\mathrm{N}$ photocatalysts, stained with methylene blue (a) or coffee (b), and exposed to visible, ultraviolet (UV), and solar light.

What is important to notice is that, no matter what type of light or stain that was used, the photocatalytic activity increases until a certain concentration of nanoparticles, after which the effect strongly decreases. These results confirm the findings of other studies [20] demonstrating that an increased concentration of photocatalyst [39] determines higher degradation rates, but the effect is diminished [40-42] by the particle size and agglomeration, and by the contaminant's type and loading.

In the case of coffee stains, the efficiency was higher for the materials treated with photocatalysts 1 and 2 , but 1 was more efficient compared to 2 . This effect could be attributed to the smaller size of photocatalyst $1(\sim 10 \mathrm{~nm})$, leading to a higher relative surface area and number of active sites.

The coffee stains are more resistant to light compared to methylene blue dye, the color differences indicating a discoloration similar to the untreated material for photocatalyst 1 , and even a stabilization of color when treating with photocatalyst 2 (Table 3). The low ability of $\mathrm{TiO}_{2}$ to decompose coffee stains was reported by other studies, probably because of the aromatic rings of components [43] which are difficult to be mineralized.

More than that, as studies have shown, the photo-degradation mechanisms are different for dyes and for natural pigments [44]. While synthetic dyes are sensitive [45] to light, and the stain discoloration is initiated by the dye itself, the natural compounds, as those found in coffee, are decomposed by reactive species, such as $-\mathrm{OH}, \mathrm{O}_{2}$ and $\mathrm{H}_{2} \mathrm{O}_{2}$ generated on the $\mathrm{TiO}_{2}$ surface [46]. Summarizing, the results demonstrate that the photocatalytic activity depends on multiple parameters, starting from the photocatalysts' characteristics, to the type of additives and contaminants. It is clear that, for each parameter, many experiments have to be conducted to establish the optimum concentration at which the photocatalyst is efficient. 


\subsection{Antibacterial Efficiency}

The antibacterial activity against $E$. coli and P. aeruginosa strains and biocompatibility performances of the materials treated with $\mathrm{TiO}_{2}-1 \% \mathrm{Fe}-\mathrm{N}$ particles were evaluated according to international standard methods. The two types of strains have been selected as the most frequent Gram-negative, fermentative and, respectively, non-fermentative bacterial species isolated from different types of nosocomial infections, i.e., urinary tract infections, pneumonia, blood stream infections, and surgical site infections [47]. The PES samples exhibited specific antimicrobial features, depending on the tested microbial strain and the incubation time (Figure 5). All particle-impregnated PES samples strongly inhibited the growth of $P$. aeruginosa after $15 \mathrm{~min}$ of incubation $(p<0.001$; two-way analysis of variance, Bonferroni test), inducing more than $1 \mathrm{log}$ decrease of viable cells counts. However, the inhibitory effect was not preserved after $24 \mathrm{~h}$, excepting a very slight inhibitory effect of HT2 ITO. Interestingly, the ITO-treated PES material proved to be the most resistant to P. aeruginosa growth after $24 \mathrm{~h}$ of incubation, probably due to specific physicochemical features of this type of acrylic binder, interfering with the later phases of the biofilm's development. In the case of the E. coli strain, although no significant inhibitory activity of samples treated with $\mathrm{TiO}_{2}-1 \% \mathrm{Fe}-\mathrm{N}$ particles was noticed after 15 min of incubation, a very strong antibacterial activity was exhibited after $24 \mathrm{~h}$ by HT1 and HT2 fabrics, which induced a decrease of more than 2 logs in the number of colony forming units (CFU)/mL (Figure 5).

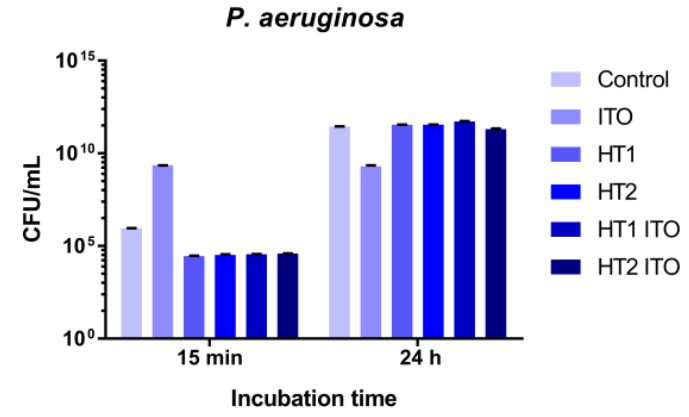

(a) P. aeruginosa

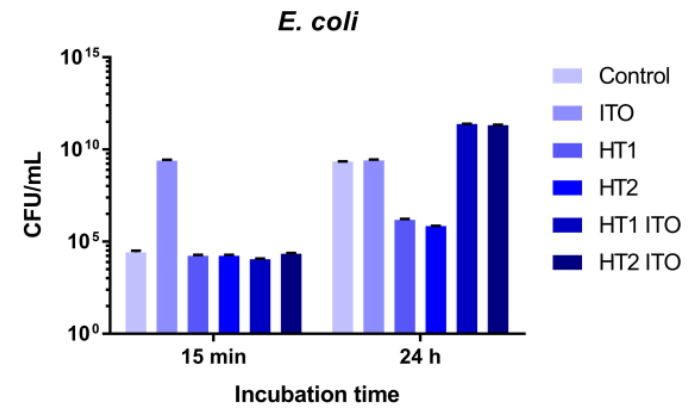

(b) E. coli

Figure 5. Graphic representation of $\mathrm{CFU} / \mathrm{mL}$ of $P$. aeruginosa (a) and E. coli (b) viable cell counts recovered after $15 \mathrm{~min}$ and $24 \mathrm{~h}$ of contact with the photocatalyst-treated polyester fabrics.

Taken together, the results regarding the antimicrobial efficiency of the treated fabrics revealed that all of these exhibited a more prominent antibacterial activity after $15 \mathrm{~min}$ of incubation against the P. aeruginosa strain. The HT1 and HT2 materials exhibited a very good antimicrobial activity against the $E$. coli strain after $24 \mathrm{~h}$ of incubation. The addition of the polyacrylic binder did not improve the antimicrobial activity of the obtained PES samples but, on the contrary, in some cases it seems to decrease it.

\subsection{Biocompatibility Results}

Before their use in developing novel textiles with improved antibacterial properties and self-cleaning capacity, these NP-treated PES samples must be strictly analyzed to check if they are biocompatible and safe for skin after direct contact or accidental release of nanoparticles from the fabric under the influence of various mechanical or chemical factors.

Therefore, to draw conclusions regarding the influence of these PES fabrics on the cytotoxicity, cell viability and cell membrane integrity, and their potential to generate inflammatory processes, multiple in vitro tests were performed on normal dermal fibroblasts. The exposure periods were selected at $6 \mathrm{~h}$ and $12 \mathrm{~h}$, as the main time intervals at which toxic effects are visible on the skin during clothes wearing or after contact with such modified fabrics. 
At $6 \mathrm{~h}$ after dermal fibroblast exposure to modified PES samples, there were no significant changes in any of the analyzed parameters (Figure 6a). The HT1 ITO sample induced a slight increase in cell viability, suggesting that the proliferative capacity of the cells have not been disrupted at all in the presence of these fabrics. Additionally, nitric oxide (NO) and lactate dehydrogenase (LDH) levels were around the control values after $6 \mathrm{~h}$ of incubation, proving that NP-treated PES fabrics did not affect cell membrane integrity nor induce inflammatory processes.

The cell viability decreased by $30 \%$ only after $12 \mathrm{~h}$ of exposure and the amount of NO released in the culture medium registered as slightly increased by $10 \%$, while the released LDH level remained unchanged compared to the control (Figure 6b). Therefore, NP-treated fabrics did not affect cell membrane integrity and the inflammatory processes induced as a response to these functional fabrics were too low to be considered significant.

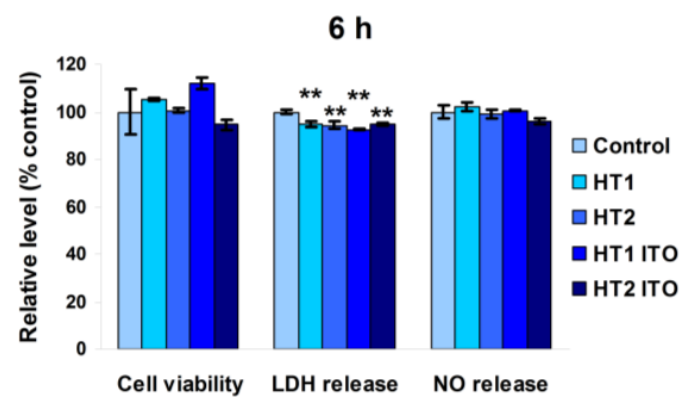

(a) $6 \mathrm{~h}$ exposure

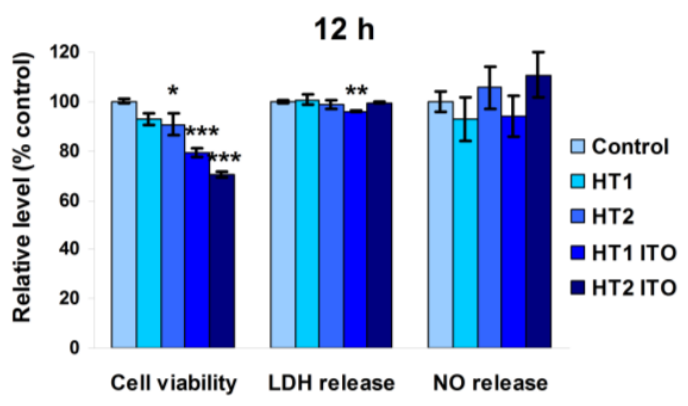

(b) $12 \mathrm{~h}$ exposure

Figure 6. Biocompatibility of PES samples as shown by cell viability, lactate dehydrogenase (LDH), and nitric oxide (NO) release assays after $6 \mathrm{~h}(\mathbf{a})$ and $12 \mathrm{~h}(\mathbf{b})$ exposure on normal skin fibroblasts. Results are expressed as the mean \pm standard deviation (SD) $(n=3)$ and represented relative to the untreated PES sample (control). ${ }^{*} p<0.05,{ }^{* *} p<0.01$ and ${ }^{* * *} p<0.001$ compared to control.

The actin cytoskeleton organization evidenced by fluorescence microscopy in Figure 7 was consistent with the results of biocompatibility tests showed in Figure 6. Thus, the cells kept their fibroblast-specific elongated morphology and established numerous focal adhesions after 6 and $12 \mathrm{~h}$ of incubation (Figure 7), which confirmed that NP-containing textiles did not affect the behavior of human dermal fibroblasts.
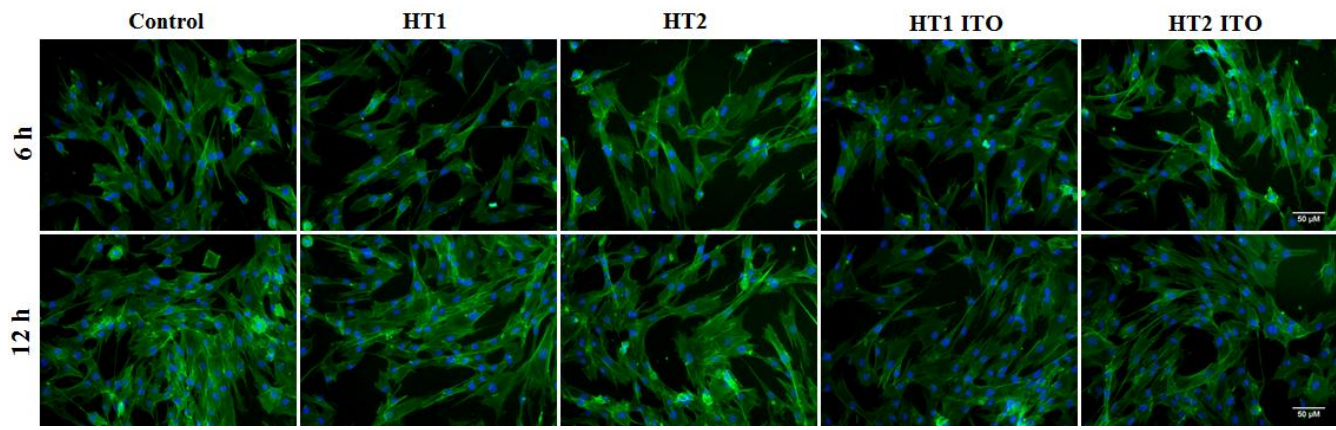

Figure 7. Actin cytoskeleton organization of dermal fibroblast cells after $6 \mathrm{~h}$ and $12 \mathrm{~h}$ of incubation with photocatalyst-treated PES samples. F-actin (green) was labeled with phalloidin-phalloidin-fluorescein isothiocyanate (FITC) and nuclei (blue) were counterstained with 4',6-diamidino-2-phenylindole dihydrochloride (DAPI). Scale bar: $50 \mu \mathrm{m}$.

\section{Discussion}

Self-cleaning and self-sanitizing coatings containing titanium dioxide are often used to obtain biocompatible fabrics with antibacterial, antifungal, and antiviral activity that could find applications 
in the biomedical field [48-50]. In this context, the purpose of the present study was the design, manufacture, and bioevaluation of polyester fabrics impregnated with $\mathrm{TiO}_{2}$ particles co-doped with $1 \%$ of Fe and $\mathrm{N}$, obtained under hydrothermal conditions at different $\mathrm{pH}$ values. The ability of different microorganisms to survive in environments characterized by strong selective pressures and their capacity to share genetic determinants, leading to increasing antimicrobial resistance, represent an important healthcare issue. The textile industry has produced antimicrobial fabrics by the addition of bactericidal compounds, such as nanoparticles, quaternary ammonia compounds, and broad-spectrum compounds, like triclosan [51]. The antimicrobial and antifungal properties of textiles treated with monometallic nanoparticles, such as copper and silver, are well established. In line with this, it has been shown that cotton and cotton/polyester textiles coated with $\mathrm{Cu}, \mathrm{Ag}$ and Ti film produced total elimination of E. coli and S. aureus from the textile surfaces [52,53]. In our recent work, we characterized novel cotton fabrics coated with dispersions of nanoscaled $\mathrm{TiO}_{2}-1 \% \mathrm{Fe}-\mathrm{N}$ particles prepared by the hydrothermal method which exhibited potent antimicrobial activity against $E$. coli, P. aeruginosa, and S. aureus [28]. In view of these results, we were able to develop in the current study novel polyester fabrics which were treated with photocatalytic $\mathrm{TiO}_{2}$ particles co-doped with iron and nitrogen atoms.

All treated fabrics described within this study inhibited the growth of Gram-negative, non-fermentative bacilli strains after $15 \mathrm{~min}$ of contact. These results demonstrated that the treated fabrics could decrease the risk of exogenous accidental contamination with $P$. aeruginosa in case of medical maneuvers with short duration, involving textiles, like changing dressings or wound washing. This could be a very significant aspect if we take into account that $P$. aeruginosa is a reputed nosocomial agent, with a very high resistance to different limitative conditions, and being very frequently transmitted in the hospital settings through contaminated materials, including textiles. After $24 \mathrm{~h}$, the inhibitory effect of microbial growth was preserved only for the HT1 and HT2 samples against E. coli. However, the ITO-treated PES samples did not show the same efficiency. This could probably be explained by the nanoparticles' agglomeration in large clusters and their covering with a polymer layer. Consequently, the number of the active sites generating reactive species involved in the photocatalytic process and the attack on bacterial cells were decreased. Therefore, further studies should be focused in finding novel ligands that could extend the duration of the antimicrobial activity of the modified textiles.

In addition to the fact that PES fabrics treated with photocatalytic $\mathrm{TiO}_{2}-1 \% \mathrm{Fe}-\mathrm{N}$ nanoparticles could provide short-term protection against microbial colonization of these materials, these modified materials were harmless for skin cells, proving good biocompatibility. LDH and NO assays are two of the most common in vitro cytotoxicity tests. The release of intracellular LDH into the culture medium as a result of cell membrane damages represents a valuable marker for cell death [54]. As long as the LDH leakage level is maintained under the $10 \%$ threshold, the effect of photocatalyst exposure can be considered insignificant for membrane toxicity [55]. Further, it is well known that NO is an important molecule involved in inflammatory responses, but it also plays a key role in the regulation of apoptotic death and cell viability. The influence of $\mathrm{NO}$ on cell viability is concentration- and cell type-dependent. It appears that higher levels induce apoptotic death, while lower or moderate concentrations protect the cells, favoring their survival [56]. Most of the previous studies have addressed the photocatalytic performance of the textiles with $\mathrm{TiO}_{2}$ coatings for self-cleaning or purification applications, but did not focus on the critical aspect of human cytotoxicity $[57,58]$. Thus, it is difficult to compare our findings, but we can state that they are in agreement with previous safety profiles revealed on macrophage, liver, and kidney cells for different prepared photocatalytic $\mathrm{TiO}_{2}$ nanoparticles and loaded on the surface of polyester-cotton fibers [59].

Taken together, we show that the treatment of PES fabrics with photocatalytic $\mathrm{TiO}_{2}-1 \% \mathrm{Fe}-\mathrm{N}$ nanoparticles could provide novel functionalized textiles harboring antibacterial and cytocompatible properties. Thus, our results highlight the potential of these modified fabrics for the development of novel materials for biomedical applications, such as wound dressings, disposable operatory fields, hospital sheets, and medical robes for preventing patients' accidental contamination with microorganisms from the hospital environment. 


\section{Materials and Methods}

\subsection{Synthesis and Characterization of Photocatalysts}

The $\mathrm{TiO}_{2}-1 \%$ Fe-N (titanium dioxide doped with 1\% iron atoms and nitrogen) photocatalysts were synthesized hydrothermally at $200{ }^{\circ} \mathrm{C}$ for $2 \mathrm{~h}$, starting with corresponding amounts of $\mathrm{FeCl}_{3} \cdot 6 \mathrm{H}_{2} \mathrm{O}$ and $\mathrm{TiCl}_{3}$. A solution of $25 \% \mathrm{NH}_{4} \mathrm{OH}$ was used to adjust the $\mathrm{pH}$ values to 8.5 for photocatalyst 1 and 5.5 for photocatalyst 2 . The resulting powders were dried in air at $105^{\circ} \mathrm{C}$ and finally calcined at $400{ }^{\circ} \mathrm{C}$ in air for $2 \mathrm{~h}$. The complete procedure was described in more details in a previous paper [28]. TEM investigations have been performed using a JEOL JEM ARM200F-Tokyo-Japan transmission electron microscope operating at $200 \mathrm{kV}$ on specimens prepared by crushing the powders in ethanol, dispersing by sonication, and dropping on lacy carbon grids.

The method to prepare the $0.5 \mathrm{~g} / \mathrm{L}$ photocatalyst dispersions and to deposit them on fabrics was previously defined by the authors [28]. Shortly, $0.2 \mathrm{~g}$ photocatalyst powder and $0.006 \mathrm{~g}$ polyvinylpyrrolidone were dispersed in $400 \mathrm{~mL}$ of distilled water in an ultrasonic bath at $40{ }^{\circ} \mathrm{C}$ for $60 \mathrm{~min}$. One hundred percent polyester woven fabric $\left(146.30 \mathrm{~g} / \mathrm{m}^{2}, 0.39 \mu \mathrm{m}\right.$ thickness) was immersed in the $0.5 \mathrm{~g} / \mathrm{L}$ photocatalyst dispersion, sonicated for $60 \mathrm{~min}$ at $40{ }^{\circ} \mathrm{C}$, and then dried in an oven at $100{ }^{\circ} \mathrm{C}$ for $60 \mathrm{~min}$. A second fabric was immersed in the used dispersion and treated to similar conditions as above. To fix the particles, the wet material was immersed in $20 \mathrm{~mL} / \mathrm{L}$ polyacrylic binder (ITOBINDER AG, abbreviated ITO in the present work, it is a self-cross linking aqueous acrylic copolymer emulsion acquired from LJ Specialties, Chesterfield, Derbyshire, UK), maintained in an ultrasound bath for $30 \mathrm{~min}$, and then dried at $100{ }^{\circ} \mathrm{C}$.

The treated fabrics were noted: HT1-PES fabric treated with $\mathrm{TiO}_{2}-1 \%$ Fe-N (photocatalyst 1), HT2-PES fabric treated with $\mathrm{TiO}_{2}-1 \% \mathrm{Fe}-\mathrm{N}$ (photocatalyst 2); HT1 ITO-PES fabric treated with TiO $2-1 \%$ Fe-N (photocatalyst 1) and ITO; HT2 ITO-PES fabric treated with $\mathrm{TiO}_{2}-1 \%$ Fe-N (photocatalyst 2) and ITO; and control PES- untreated PES fabric.

The morphology of the fabrics' surfaces treated with photocatalysts and the amount of deposited particles were analyzed by SEM (Quanta 200, FEI, Eindhoven, The Netherlands) equipped with an EDX detector, which was used to evaluate the elemental composition of the coated textiles. EDX spectrum measurements were performed on fabric samples attached to a carbon conductive tape with $10 \mathrm{kV}$ accelerating voltage. The spectral data were collected from an area of $0.0379 \mathrm{~mm} \times 0.0296 \mathrm{~mm}$ with $512 \times 400$ resolution, at $8000 \times$ magnification. After ZAF (the acronym for atomic number effects, absorption and fluorescence) correction coefficients, the atomic and mass ratios of titanium were calculated using the software Genesis Imaging/Mapping 5.21.

Evaluation of the photocatalytic performance was performed by staining the control materials and those treated with photocatalysts with a $0.01 \mathrm{~g} / \mathrm{L} \mathrm{MB}$ solution and coffee (three teaspoons of coffee in $500 \mathrm{~mL}$ water). The stained fabrics were half covered with paper and were exposed to UV light $(254 \mathrm{~nm})$ in a completely closed cabinet and in a visible light laboratory equipment (Xenotest, $1000 \mathrm{~W}$ xenon arc lamp, irradiance $4.5 \mathrm{~mW} / \mathrm{cm}^{2}$ at 300-400 nm, Heraeus Industrietechnik, Hanau, Germany). Additionally, the fabrics were exposed to natural solar radiation. Chromaticity coordinates of exposed and non-exposed material were measured by a UV-Vis Hunterlab spectrophotometer (Hunter Associates Laboratory, Reston, VA, USA), with a CIELAB 1976 color space and D65-light source.

\subsection{Antimicrobial Activity Assay}

The antimicrobial activity of the obtained textiles was assessed against Gram-negative bacterial reference strains, i.e., P. aeruginosa ATCC 27853 and E. coli ATCC 8739. The microbial strains were purchased from the American Type Culture Collection (ATCC, Manassas, VA, USA). Glycerol stocks were streaked on Luria Bertani (LB) agar in order to obtain $24 \mathrm{~h}$ cultures for further experiments. The biofilm development was assessed after two incubation times, i.e., $15 \mathrm{~min}$ and $24 \mathrm{~h}$, in accordance with the ASTME 2149-10 standard for the assessment of the antimicrobial activity of agents immobilized in dynamic testing conditions. For this purpose, the textile materials were cut into equal circular pieces 
of $8 \mathrm{~mm}$ diameter and sterilized by autoclaving at $121^{\circ} \mathrm{C}$ for $15 \mathrm{~min}$. The sterile pieces were then immersed in one $\mathrm{mL}$ of microbial suspensions of $\sim 10^{7} \mathrm{CFU} / \mathrm{mL}$ performed in sterile saline and left in contact for $15 \mathrm{~min}$ and $24 \mathrm{~h}$. At the end of exposure, the microbial suspensions incubated with the tested samples were vortexed and $10 \mu \mathrm{L}$ of serial ten-fold dilutions of the obtained suspension were plated in triplicate on LB agar. After $24 \mathrm{~h}$ of incubation at $37^{\circ} \mathrm{C}$, viable cell counts were performed and the $\mathrm{CFU} / \mathrm{mL}$ values for each sample were established.

\subsection{In Vitro Biocompatibility Assessment}

CCD-1070Sk normal human skin fibroblasts (purchased from American Type Culture Collection (ATCC), Cat. No. CRL-2091, Rockville, MD, USA) were cultured at low passage in complete Eagle's minimum essential medium (MEM; Gibco/Invitrogen, Carlsbad, CA, USA) containing $10 \%$ fetal bovine serum (FBS; Gibco/Invitrogen, Carlsbad, CA, USA) at $37{ }^{\circ} \mathrm{C}$ in a humidified atmosphere with $5 \% \mathrm{CO}_{2}$. Fibroblasts were grown to $70 \%-80 \%$ confluence within five days, then detached with $0.25 \%$ trypsin- $0.03 \%$ ethylenediaminetetraacetic acid (EDTA) and transferred to new culture flasks. For biocompatibility assessment, the cells were seeded at a density of $2 \times 10^{4} \mathrm{cells} / \mathrm{cm}^{2}$ in a 24-well plate and left to adhere overnight. The polyester fabrics treated with $\mathrm{TiO}_{2}-1 \% \mathrm{Fe}-\mathrm{N}$ samples, cut into $1 \times 1 \mathrm{~cm}^{2}$ pieces, sterilized at $120^{\circ} \mathrm{C}$ for $20 \mathrm{~min}$, and exposed to a light source for $30 \mathrm{~min}$ were soaked in culture medium and placed over the attached fibroblasts without disturbing the cells as it was previously reported for other materials [48]. After 6 and $12 \mathrm{~h}$ of incubation, cell morphology and viability were evaluated, while cytotoxicity tests were also performed. The results were expressed relative to the untreated PES fabric used as a control.

The cell viability was measured using the 3-(4,5-dimethylthiazol-2-yl)-2,5-diphenyltetrazolium bromide (MTT; Sigma-Aldrich, St. Louis, MO, USA) assay (from the battery of cytotoxicity tests described in ISO 10993-5:2009, part 5) which is based on the quantification of NAD(P)H-dependent cellular oxido-reductase enzymes activity in the viable cells. Briefly, the culture medium and polyester samples were removed at the end of the time exposure and the cells were incubated with $1 \mathrm{mg} / \mathrm{mL}$ MTT solution for $3 \mathrm{~h}$ at $37^{\circ} \mathrm{C}$ and $5 \% \mathrm{CO}_{2}$. The purple formazan crystals formed in the viable cells were dissolved with 2-propanol (Sigma-Aldrich, St. Louis, MO, USA) and the absorbance was measured at $595 \mathrm{~nm}$ using a microplate reader (GENios Tecan, Grödig, Austria).

The LDH amount released in culture medium was assessed as a measure of cell membrane integrity using a commercial kit (TOX7, Sigma-Aldrich, St. Louis, MO, USA) according to the manufacturer's instructions. Volumes of $50 \mu \mathrm{L}$ of culture supernatants were incubated with a $100 \mu \mathrm{L}$ mix composed from equal parts of dye, substrate, and cofactor for $30 \mathrm{~min}$ in dark. The reaction was stopped by adding $15 \mu \mathrm{L}$ of $1 \mathrm{~N} \mathrm{HCl}$ and the absorbance was read at $490 \mathrm{~nm}$ using a GENios Tecan microplate reader (Tecan, Grödig, Austria).

The level of NO released in the culture medium as an indicator of inflammation was determined using the Griess reagent. Culture supernatants were mixed with an equal volume of Griess reagent, which is a stoichiometric solution $(v / v)$ of $0.1 \%$ naphthylethylendiamine dihydrochloride and $1 \%$ sulphanilamide in $5 \% \mathrm{H}_{3} \mathrm{PO}_{4}$, and absorbance was read at $550 \mathrm{~nm}$ using a GENios Tecan microplate reader. $\mathrm{NO}$ concentration was extrapolated on a $\mathrm{NaNO}_{2}$ standard curve.

Cell spreading and actin cytoskeleton morphology were monitored via fluorescence imaging using cells fixed with $4 \%$ paraformaldehyde for $20 \mathrm{~min}$ and permeabilized with $0.1 \%$ Triton $\mathrm{X}-100-2 \%$ bovine serum albumin for $1 \mathrm{~h}$. Filamentous actin (F-actin) was labeled with $20 \mu \mathrm{g} / \mathrm{mL}$ phalloidin conjugated with FITC (Sigma-Aldrich, Munich, Germany) and nuclei were stained with $2 \mu \mathrm{g} / \mathrm{mL}$ 4',6-diamidino-2-phenylindole (DAPI) (Molecular Probes, Life Technologies, Carlsbad, CA, USA). Images were captured using an inverse fluorescence microscope Olympus IX71 (Olympus, Tokyo, Japan). 


\subsection{Statistical Analysis}

The antibacterial efficiency and cell culture assays were performed in triplicate, and data were shown as mean $\pm \mathrm{SD}$. The statistical significance was analyzed by Student's $t$-test or two-way ANOVA followed by Bonferroni's post hoc test using GraphPad Prism 5 (GraphPad software Inc., La Jolla, CA, USA), and a value of $p<0.05$ was considered significant.

\section{Conclusions}

In this work, we revealed that the physical properties of the polyester fabrics treated with nitrogen and iron co-doped $\mathrm{TiO}_{2}$ nanoparticles prepared by hydrothermal method were not significantly modified. Also, the use of a polyacrylic binder allowed the deposition of a higher amount of nanoparticles on the textile surface and the improvement of the photo-discoloration efficiency under visible and solar radiation due to the extended absorption of light in the visible area. Finally, our results highlighted the biocompatibility on human skin cells of PES fabrics modified with photocatalytic $\mathrm{TiO}_{2}-1 \% \mathrm{Fe}-\mathrm{N}$ nanoparticles which could be further used as novel materials for biomedical applications, such as wound dressings, disposable operatory fields, hospital sheets, and medical robes for preventing patients.

Acknowledgments: This work was supported by a research grant from the Executive Unit for Financing Higher Education, Research, Development and Innovation (UEFISCDI) in the frame of Partnership PN II Program (Project No. 87/2014-CLEANTEX).

Author Contributions: Ionela Cristina Nica performed the biochemical experiments, analyzed the data and drafted the manuscript. Miruna Silvia Stan, Marcela Popa, Gratiela G. Pircalabioru, Ovidiu G. Iordache, Elena Varzaru, Marcel Feder, Florin Vasiliu, Ionel Mercioniu and Lucian Diamandescu performed the experiments. Anca Dinischiotu, Iuliana Dumitrescu, Mariana Carmen Chifiriuc, Veronica Lazar, Eugenia Bezirtzoglou and Lucian Diamandescu conceived and designed the study and wrote the manuscript.

Conflicts of Interest: The authors declare no conflict of interest.

\section{References}

1. Joost, U.; Juganson, K.; Visnapuu, M.; Mortimer, M.; Kahru, A.; Nommiste, E.; Joost, U.; Kisand, V.; Ivask, A. Photocatalytic antibacterial activity of nano- $\mathrm{TiO}_{2}$ (anatase)-basedthin films: Effects on Escherichia coli cells and fatty acids. J. Photochem. Photobiol. B 2015, 142, 178-185. [CrossRef] [PubMed]

2. Tateda, K. Antibiotic-resistant bacteria and new directions of antimicrobial chemotherapy. Rinsho Byori 2012, 60, 443-448. [PubMed]

3. Tanwar, J.; Das, S.; Fatima, Z.; Hameed, S. Multidrug resistance: An emerging crisis. Interdiscip. Perspect. Infect. Dis. 2014, 2014, 541340. [CrossRef] [PubMed]

4. Sunada, K.; Watanabe, T.; Hashimoto, K. Studies on photokilling of bacteria on $\mathrm{TiO}_{2}$ thin film. J. Photochem. Photobiol. A 2003, 156, 227-233. [CrossRef]

5. Tryba, B. Increase of the photocatalytic activity of $\mathrm{TiO}_{2}$ by carbon and iron modifications. Int. J. Photoenergy 2008, 2008, 721824. [CrossRef]

6. Li, G.; Nie, X.; Chen, J.; Jiang, Q.; An, T.; Wong, P.K.; Zhang, H.; Zhao, H.; Yamashita, H. Enhanced visible-light-driven photocatalytic inactivation of Escherichia coli using $g-\mathrm{C}_{3} \mathrm{~N}_{4} / \mathrm{TiO}_{2}$ hybrid photocatalyst synthesized using a hydrothermal-calcination approach. Water Res. 2015, 15, 343-354. [CrossRef] [PubMed]

7. Diamandescu, L.; Vasiliu, F.; Mihaila, D.T.; Feder, M.; Vlaicu, A.M.; Teodorescu, C.M.; Macovei, D.; Enculescu, I.; Parvulescu, V.; Vasile, E. Structural and photocatalytic properties of iron and europium doped $\mathrm{TiO}_{2}$ nanoparticles obtained under hydrothermal conditions. Mater. Chem. Phys. 2008, 112, 146-153. [CrossRef]

8. Banerjee, A.N. The design, fabrication, and photocatalytic utility of nanostructured semiconductors: Focus on $\mathrm{TiO}_{2}$-based nanostructures. Nanotechnol. Sci. Appl. 2011, 4, 35-65. [CrossRef] [PubMed]

9. Zhang, M.; Yu, X.; Lu, D.; Yang, J. Facile synthesis and enhanced visible light photocatalytic activity of $\mathrm{N}$ and $\mathrm{Zr}$ co-doped $\mathrm{TiO}_{2}$ nanostructures from nanotubular titanic acid precursors. Nanoscale Res. Lett. 2013, 8, 543. [CrossRef] [PubMed] 
10. Glampedaki, P.; Calvimontes, A.; Dutschk, V.; Warmoeskerken, M.M. Polyester textile functionalization through incorporationof $\mathrm{pH} /$ thermo-responsive microgels. Part II: Polyester functionalization and characterization. Mater. Sci. 2012, 47, 2078-2087. [CrossRef] [PubMed]

11. Mihailovic, D.; Saponjic, Z.; Radoicic, M.; Radetic, T.; Jovancic, P.; Nedeljkovic, J.; Radetic, M. Functionalization of polyester fabrics with alginates and $\mathrm{TiO}_{2}$ nanoparticles. Carbohydr. Polym. 2010, 79, 526-532. [CrossRef]

12. Lam, Y.L.; Kan, C.W.; Yuen, C.W.M. Effect of concentration of titanium dioxide acting as catalyst or co-catalyst on the wrinkle-resistant finishing of cotton fabric. Fiber Polym. 2010, 11, 551-558. [CrossRef]

13. Radetic, M. Functionalization of textile materials with $\mathrm{TiO}_{2}$ nanoparticles. J. Photochem. Photobiol. C 2013, 16, 62-76. [CrossRef]

14. Ilic, V.; Saponjic, Z.; Vodnik, V.; Lazovic, S.; Dimitrijevic, S.; Jovancic, P.; Nedeljkovic, J.M.; Radetic, M. Bactericidal efficiency of silver nanoparticles deposited onto radio frequency plasma pretreated polyester fabrics. Ind. Eng. Chem. Res. 2010, 49, 7287-7293. [CrossRef]

15. Cai, Y.; Stromme, M.; Welch, K. Photocatalytic antibacterial effects are maintained on resin-based $\mathrm{TiO}_{2}$ nanocomposites after cessation of UV irradiation. PLoS ONE 2013, 8, e75929. [CrossRef] [PubMed]

16. Ashraf, M.; Champagne, P.; Campagne, C.; Perwuelz, A.; Dumont, F.; Leriche, A. Study the multi self-cleaning characteristics of $\mathrm{ZnO}$ nanorods functionalized polyester fabric. J. Ind. Text. 2016, 45, 1440-1456. [CrossRef]

17. Vucetic, S.B.; Rudic, O.L.; Markov, S.L.; Bera, O.J.; Vidakovic, A.M.; Skapin, A.S.S.; Ranogajec, J.G. Antifungal efficiency assessment of the $\mathrm{TiO}_{2}$ coating on facade paints. Environ. Sci. Pollut. Res. 2014, 21, 11228-11237. [CrossRef] [PubMed]

18. Haghighi, F.; Mohammadi, S.R.; Mohammadi, P.; Hosseinkhani, S.; Shidpour, R. Antifungal activity of $\mathrm{TiO}_{2}$ nanoparticles and EDTA on Candida albicans biofilms. Infect. Epidemiol. Med. 2013, 1, 33-38.

19. Tang, B.; Wang, J.; Xu, S.; Afrin, T.; Xu, W.; Sun, L.; Wang, X. Application of anisotropic silver nanoparticles: Multifunctionalization of wool fabric. J. Colloid Interface Sci. 2011, 356, 513-518. [CrossRef] [PubMed]

20. Saad, S.R.; Mahmed, N.; Abdullah, M.M.B.; Sandu, A.V. Self-cleaning technology in fabric: A review. IOP Conf. Ser. Mater. Sci. Eng. 2016, 133, 012028. [CrossRef]

21. Haji, A.; Shoushtari, A.M.; Mazaheri, F.; Tabatabaeyan, S.E. Environmentally Friendly Pretreatment for Enhanced Coating of $\mathrm{TiO}_{2}$ Nanoparticles on PET/Wool Fabric. In Proceedings of the International Conference on Chemical, Civil and Environmental Engineering (CCEE'2014), Singapore, Singapore, 18-19 November 2014.

22. Saravanan, D. UV protection textile materials. AUTEX Res. J. 2007, 7, 53-62.

23. Zgura, I.; Frunza, S.; Frunza, L.; Enculescu, M.; Florica, C.; Cotorobai, V.F.; Ganea, C.P. Polyester fabrics covered with amorphous titanium dioxide layers: Combining wettability measurements and photoinduced hydrophylicity to assess their surface properties. Romanian Rep. Phys. 2016, 68, 259-269.

24. Ma, H.; Gao, Q.; Gao, C.; Bao, W.; Ge, M. Facile synthesis of electroconductive $\mathrm{AZO} @ \mathrm{TiO}_{2}$ whiskers and their application in textiles. J. Nanomater. 2016, 2016, 5940618. [CrossRef]

25. Patra, J.K.; Gouda, S. Application of nanotechnology in textile engineering: An overview. J. Eng. Technol. Res. 2013, 5, 104-111. [CrossRef]

26. Yetisen, A.K.; Qu, H.; Manbachi, A.; Butt, H.; Dokmeci, M.R.; Hinestroza, J.P.; Skorobogatiy, M.; Khademhosseini, A.; Yun, S.H. Nanotechnology in textiles. ACS Nano 2016, 10, 3042-3068. [CrossRef] [PubMed]

27. Banerjee, S.; Dionysiou, D.D.; Pillai, S.C. Self-cleaning applications of $\mathrm{TiO}_{2}$ by photo-induced hydrophilicity and photocatalysis. Appl. Catal. B 2015, 176, 396-428. [CrossRef]

28. Stan, M.S.; Nica, I.C.; Dinischiotu, A.; Varzaru, E.; Iordache, O.G.; Dumitrescu, I.; Popa, M.; Chifiriuc, M.C.; Pircalabioru, G.G.; Lazar, V.; et al. Photocatalytic, antimicrobial and biocompatibility features of cotton knit coated with Fe-N-doped titanium dioxide nanoparticles. Materials 2016, 9, 789. [CrossRef]

29. Messaoud, M.; Chadeau, E.; Brunon, C.; Ballet, T.; Rappenne, L.; Roussel, F.; Leonard, D.; Oulahal, N.; Langlet, M. Photocatalytic generation of silver nanoparticles and application to the antibacterial functionalization of textile fabrics. J. Photochem. Photobiol. A 2010, 215, 147-156. [CrossRef]

30. Hsu, B.C. Preparation, Characterisation and Visible Light Responsive Photocatalytic Activity of Iron/Nitrogen Doped Titanium Dioxide Nanocrystalline. Ph.D. Thesis, National Taipei University of Technology, Taipei, Taiwan, 2009. 
31. Zhanga, Y.; Chenga, K.; Lva, F.; Huanga, H.; Feib, B.; Hea, Y.; Yec, Z.; Shen, B. Photocatalytic treatment of 2,4,6-trinitotoluene in red water by multi-doped $\mathrm{TiO}_{2}$ with enhanced visible light photocatalytic activity. Colloids Surf. A 2014, 452, 103-108. [CrossRef]

32. Cong, Y.; Zhang, J.; Chen, F.; Anpo, M.; He, D. Preparation, photocatalytic activity, and mechanism of nano-TiO ${ }_{2}$ co-doped with nitrogen and iron (III). Phys. Chem. C 2007, 111, 10618-10623. [CrossRef]

33. Klug, H.P.; Alexander, L.E. X-ray Diffraction Procedures for Polycrystalline and Amorphous Materials; Wiley: New York, NY, USA, 1966; p. 491.

34. Lee, H.L.; Kim, J.; Park, C.H. Fabrication of self-cleaning textiles by $\mathrm{TiO}_{2}$-carbon nanotube treatment. Text. Res. J. 2014, 84, 267-278. [CrossRef]

35. International Organization for Standardization. Joint ISO/CIE Standard: Colorimetry—Part 4: CIE $1976 L^{*} a^{*} b^{*}$ Colour Space; ISO 11664-4:2008(E)/CIE S 014-4/E: 2007; ISO: Geneva, Switzerland, 2007.

36. Larumbe, S.; Monge, M.; Gomez-Polo, C. Comparative study of (N, Fe) doped $\mathrm{TiO}_{2}$ photocatalysts. Appl. Surf. Sci. 2015, 327, 490-497. [CrossRef]

37. Zhuomao, Z.; Baoan, B.; Haifeng, S. Effect of $\mathrm{N}$ and Fe codoping on the electronic structure and optical properties of $\mathrm{TiO}_{2}$ from first-principles study. J. Semicond. 2015, 36, 102003.

38. Zhang, Y.; Shen, H.; Liu, Y. Cooperation between $\mathrm{N}$ and $\mathrm{Fe}$ in co-doped $\mathrm{TiO}_{2}$ photocatalyst. Res. Chem. Intermed. 2016, 42, 687. [CrossRef]

39. Muruganandham, M.; Swaminathan, M. Photocatalytic decolourisation and degradation of reactive orange 4 by $\mathrm{TiO}_{2}$-UV process. Dyes Pigment. 2006, 68, 133-142. [CrossRef]

40. Zhang, T.; Oyama, T.; Horikoshi, S.; Hidaka, H.; Zhao, J.; Serpone, N. Photocatalyzed N-demethylation and degradation of methylene blue in titania dispersions exposed to concentrated sunlight. Sol. Energy Mater. Sol. Cells 2002, 73, 287-303. [CrossRef]

41. Daneshvar, N.; Salari, D.; Khataee, A.R. Photocatalytic degradation of azo dye acid red 14 in water on $\mathrm{ZnO}$ as an alternative catalyst to $\mathrm{TiO}_{2}$. J. Photochem. Photobiol. A 2004, 162, 317-322. [CrossRef]

42. Sohabi, M.R.; Ghavami, M. Photocatalytic degradation of direct red 23 dye using UV/TiO 2 : Effect of operational parameters. J. Hazard. Mater. 2008, 153, 1235-1239. [CrossRef] [PubMed]

43. Meilert, K.T.; Laub, D.; Kiwi, J. Photocatalytic self-cleaning of modified cotton textiles by $\mathrm{TiO}_{2}$ clusters attached by chemical spacers. J. Mol. Catal. A 2005, 237, 101-108. [CrossRef]

44. Bozzi, A.; Yuranova, T.; Guasaquillo, I.; Kiwi, J. Self-cleaning of modified cotton textiles by $\mathrm{TiO}_{2}$ at low temperatures under daylight irradiation. J. Photochem. Photobiol. A 2005, 174, 156-164. [CrossRef]

45. Adams, D.; Brus, L.; Chidsey, C.; Creager, S.; Creutz, C.; Kagan, C.; Kamat, P.V.; Lieberman, M.; Lindsay, S.; Marcus, R.; et al. Charge transfer on the nanoscale: Current status. J. Phys. Chem. B 2003, 107, 6668-6697. [CrossRef]

46. Sychev, A.Y.; Isak, V.G. Iron compounds and the mechanisms of the homogeneous catalysis of the activation of $\mathrm{O}_{2}$ and $\mathrm{H}_{2} \mathrm{O}_{2}$ and of the oxidation of organic substrates. Russ. Chem. Rev. 1995, 64, 1105-1129. [CrossRef]

47. Gaynes, R.; Edwards, J.R. National Nosocomial Infections Surveillance System. Overview of nosocomial infections caused by gram-negative bacilli. Clin. Infect. Dis. 2005, 41, 848-854. [PubMed]

48. Prabhakar, P.K.; Raj, S.; Anuradha, P.R.; Sawant, S.N.; Doble, M. Biocompatibility studies on polyaniline and polyaniline-silver nanoparticle coated polyurethane composite. Colloids Surf. B 2011, 86, 146-153. [CrossRef] [PubMed]

49. Barletta, M.; Vesco, S.; Tagliaferri, V. Self-cleaning and self-sanitizing coatings on plastic fabrics: Design, manufacture and performance. Colloids Surf. B 2014, 120, 71-80. [CrossRef] [PubMed]

50. Parthasarathi, V.; Thilagavathi, G. Developing antiviral surgical gown using nonwoven fabrics for health care sector. Afr. Health Sci. 2013, 13, 327-332. [CrossRef] [PubMed]

51. McArthur, J.V.; Tuckfield, R.C.; Baker-Austin, C. Antimicrobial textiles. Handb. Exp. Pharmacol. 2012, 211, 135-152.

52. Chattopadhyay, D.P.; Patel, B.H. Effect of nanosized colloidal copper on cotton fabric. J. Eng. Fiber Fabr. 2010, 5, 1-6.

53. Aslan, N.; Şentürk, K.; Şen, T.; Çoruhlu, T.; Vartürk, İ.; Şeker, S.; Shahidi, S.; Dobrovolskiy, A.M.; Tsiolko, V.V.; Matsevich, S.V.; et al. Investigation of antimicrobial activity and morphological properties of metal coated textile surfaces. Probl. Atom. Sci. Technol. 2014, 20, 208-211. 
54. Fotakis, G.; Timbrell, J.A. In vitro cytotoxicity assays: Comparison of LDH, neutral red, MTT and protein assay in hepatoma cell lines following exposure to cadmium chloride. Toxicol. Lett. 2006, 160, 171-177. [CrossRef] [PubMed]

55. Beyerle, A.; Schulz, H.; Kissel, T.; Stoeger, T. Screening strategy to avoid toxicological hazards of inhaled nanoparticles for drug delivery: The use of $\alpha$-quartz and nano zinc oxide particles as benchmark. JPCS 2009, 151, 012034. [CrossRef]

56. Bosca, L.; Zeini, M.; Traves, P.G.; Hortelano, S. Nitric oxide and cell viability in inflammatory cells: A role for NO in macrophage function and fate. Toxicology 2005, 208, 249-258. [CrossRef] [PubMed]

57. Pasqui, D.; Barbucci, R. Synthesis, characterization and self-cleaning properties of titania nanoparticles grafted on polyester fabrics. J. Photochem. Photobiol. A 2014, 274, 1-6. [CrossRef]

58. Ortelli, S.; Costa, A.L.; Dondi, $\mathrm{M}$. $\mathrm{TiO}_{2}$ nanosols applied directly on textiles using different purification treatments. Materials 2015, 8, 7988-7996. [CrossRef]

59. Cui, G.; Xin, Y.; Dong, M.; Li, J.; Wang, P.; Zhai, S.; Dong, Y.; Jia, J.; Yan, B. Safety profile of TiO2-based photocatalytic nanofabrics for indoor formaldehyde degradation. Int. J. Mol. Sci. 2015, 16, 27721-27729. [CrossRef] [PubMed]

(C) 2016 by the authors; licensee MDPI, Basel, Switzerland. This article is an open access article distributed under the terms and conditions of the Creative Commons Attribution (CC-BY) license (http:/ / creativecommons.org/licenses/by/4.0/). 